\title{
Hours of work and retirement behaviour
}

\author{
C Sofia Machado ${ }^{1 *}$ and Miguel Portela ${ }^{2}$
}

\footnotetext{
* Correspondence: cmachado@ipca.pt ${ }^{1}$ Instituto Politécnico do Cávado e do Ave and NIPE, Campus do IPCA, Barcelos 4750-810, Portugal Full list of author information is available at the end of the article
}

\begin{abstract}
Using a novel dataset from the 2006 Portuguese Labour Force Survey this paper examines the impact of a voluntary reduction in hours of work, before retirement, on the moment of exit from the labour force. If, as often suggested, flexibility in hours of work is a useful measure to postpone retirement, then a reduction in working hours should be associated with retirement at later ages. Results prove otherwise suggesting that reducing hours of work before retirement is associated with early exits from the labour force. A reduction in hours of work seems to signal the worker's wish to retire sooner rather than to announce the desire of remaining in the labour market. This result may enclose the need for some alternative policy strategies regarding working hours.

JEL codes: J14; J26; J22; J21

Keywords: Ageing; Retirement; Working hours; Older workers
\end{abstract}

\section{Introduction}

Population ageing is increasing the ratio of retirees to workers rising sustainability issues to Social Security systems. To ease financial pressures as well as to increase older workers' labour force participation policy makers have been promoting the expansion of working lives finding measures that make postponed labour market exit attractive.

This has been enforced through the elimination of mandatory retirement, the adoption of age discrimination legislation ${ }^{1}$ and/or increasing legal retirement age. Nonetheless, the effect of these measures on older workers' labour supply is not straightforward. For instance, Shannon and Grierson (2004) show that making compulsory retirement illegal would have a small impact on the size of the older workforce and, for that reason, such a policy alone would not solve the problems associated with an ageing population and the consequent reduction in the share of the population employed, while Ashenfelter and Card (2002), studying the effect of the elimination of mandatory retirement at age 70 on faculty retirement patterns, conclude that such elimination decreased by approximately two thirds the retirement rates of 70 and 71 year olds.

On the other hand, Adams (2004) suggests that age discrimination legislation increases employment among individuals that are in the legally protected age ranges and that there is a decline in retirement among the protected workers. Also, Neumark and Stock (1999) show that age discrimination laws lead to steeper age-earnings profiles in the labour market and that they strengthen the relationship between workers and firms, leading to the adoption of Lazear (1979) contracts. Furthermore, the authors find that age discrimination legislation increases the relative employment of older workers.

C 2014 Machado and Portela; licensee Springer. This is an Open Access article distributed under the terms of the Creative Commons Attribution License (http://creativecommons.org/licenses/by/2.0), which permits unrestricted use, distribution, and reproduction in any medium, provided the original work is properly credited. 
Focusing on the labour demand implications of a change in the legal retirement age for women in Portugal, Martins et al. (2009) find that older women affected by the new law faced virtually no change in wages and working hours.

There seems to be no unique and effective instrument to achieve a longer and higher participation of older individuals in the labour force. Making use of survival analysis techniques this paper brings another variable to the discussion on active ageing policies: it studies the impact of a reduction in hours of work before retirement on the age of exit from the labour force. Indeed, combining a reduction in working hours with increased leisure time at older ages may motivate individuals to work longer while gradually withdrawing from the labour market. As individuals age, their preference for work and leisure experience a change since older workers may get higher satisfaction from additional hours of leisure and less hours of work than younger workers. Also, due to health constraints or care obligations, as workers age they may want to reduce their hours of work. This change in the valuation of time implies a change in reservation wages over the life cycle, which influences the labour force participation decision. ${ }^{2}$

If workers could freely choose hours of work they would prefer to gradually reduce their time at work as they age (Gustman and Steinmeier 2004). Since the decision does not depend solely on the individual's will, gradual retirement is not as common as workers would like it to be (Hutchens and Grace-Martin 2006). Although there is evidence for the United States that some workers engage in 'part-time' retirement by working fewer hours in the years prior to complete withdrawal from the labour force (Ruhm 1990; Burtless and Moffitt 1985; Gustman and Steinmeier 1984), most people move directly from full-time work to full-time retirement (Hutchens and Grace-Martin 2006). As Gielen (2009) notes, a discrete drop in hours of work is only observed at the time of retirement, not before.

Given that most often workers face the choice of working full-time or no time (retirement), the constraint in hours of work may influence the labour force participation decision. In fact, there are broad indications suggesting that reduced hours of work would contribute to raise employment rates of older individuals. In the European Union, older workers are already over-represented in part-time employment and Member States, like Sweden, with higher shares of older workers in part-time employment tend to present higher employment rates for the 55-64 age group. However, part-time employment is not very common in the Portuguese labour market ${ }^{3}$ and, nevertheless, the economy shows high employment rates for older individuals.

Despite the fact that flexibility in hours of work is perceived to be a relevant policy mechanism to increase older individuals' labour force participation, few studies focused on its effect on labour supply. Among these, Gustman and Steinmeier (2004) show that working hours' flexibility extends the working lives of older workers, but produces only a small net increase in labour supply. Gielen (2009) finds that, especially for full-time workers, over-employed older women (those reporting that they wish to work fewer hours than the actual hours of work) leave the labour force prematurely due to the absence of gradual retirement opportunities. Nonetheless, a striking finding is that flexibility in hours of work would result in a reduction of older workers' labour supply since the increase in labour participation of older workers due to the extension of their working careers is cancelled out by a decline in working hours of over-employed older individuals. 
From a labour demand point of view, the work by Hutchens and Grace-Martin (2006) studies how and why establishments differ in their willingness to permit an older worker to take phased retirement. Phased retirement is perceived to be a way of encouraging older workers to extend their working lives. In this sense, workers reduce their working hours without changing employers (Hutchens and Papps 2005). The former authors conclude that employers are willing to permit phased retirement but primarily as an informal arrangement. Opportunities for phased retirement are greater in establishments that employ part-time workers, allow job sharing and have flexible starting times (this latter result is also obtained by Blau and Shvydko 2007).

If flexibility in hours of work, as a means of gradual retirement, can effectively delay the exit from the labour force then workers who actually take advantage of such flexibility are expected to leave the labour market later in their lives.

Overall, retirement decisions are influenced by individual characteristics, demographic factors, and financial incentives (Mitchell and Fields 1984; Dugan 1984; Belloni and Rob 2008), health conditions (Burtless and Quinn 2000; Bartel and Sicherman 1993; Hanoch and Honig 1983; Quinn 1977) and labour market constraints (Osberg 1993; Bartel and Sicherman 1993; Friedberg 2003; Dorn and Sousa-Poza 2009). This paper examines the influence of working hours' reduction before retirement on the retirement decisions of older individuals and intends to provide an answer to the following questions: is the reduction in hours of work associated with retirement at later ages? Can it be used to extend older workers' labour force participation and delay the complete withdraw from the labour force? We find that a voluntarily reduction of working hours is associated with exit from the labour market at earlier ages.

The main contribution of this research is to explore the relevance of working hours' reduction on the retirement behaviour of older individuals. No such study exists for Portugal and, hence, besides the novelty of this research for the Portuguese labour market it is also a new contribution to the incipient literature on the subject. Additionally, we take advantage of a recent and, to our knowledge, not yet used inquiry called "Transition to Retirement", conducted simultaneously with the 2006 Portuguese Labour Force Survey.

The paper proceeds as follows. The next section provides an overview of the major legislation changes on retirement benefits eligibility in Portugal. Section 3 describes the data. Section 4 presents the model and the empirical strategy. Results are shown in Section 5. A summary and discussion conclude the paper.

\section{Legal setting on retirement in Portugal}

To accommodate demographic ageing and its impact on the Social Security system the Portuguese government has approved several legislation changes concerning retirement over the last fifteen years.

Since 1999, 65 years is the minimum legal age that grants access to full retirement pension both for male and female workers in Portugal. By the end of 1993, the promulgation of a legal diploma set a gradual standardization of the legal retirement age (LRA) for both men and women, with effectiveness from 1994 onward. Until then, the LRA was 65 years for men and 62 years for women, and this law increased the LRA for women by six months every year until reaching 65 years old (the LRA by 1999). Other major changes introduced by the law were, on one hand, a raise from 10 to 15 in the 
required number of years with payments to Social Security for a worker to become eligible for retirement benefits and, on the other hand, a change on the pensions' method of computation.

At the beginning of 1999, and in the course of macroeconomic growth, the age of access to retirement was rendered more flexible, according to contributions' profiles. In this sense, a new law made it possible for workers at least 55 years old and a working career of 30 complete calendar years to become eligible for pension benefits. Even though there was a reduction factor linked to early retirement pensions, this flexibility imposed significant financial pressure on the Social Security system. As a consequence, the legal norms that allowed access to a pension before the worker reached the legal retirement age were suspended in 2005. Early retirement schemes became once again possible in 2007, over a new law that was published for discussion in November 2006, but with severe penalties imposed to pensions. The 2007 law also prohibits the accumulation of early retirement pension earnings with labour earnings if the worker remains in the same firm or corporation.

Through legal changes, policy makers are trying to delay older workers' exit from the labour force.

An important feature of the Portuguese legislation on retirement is that there is no possibility of partial retirement, that is, workers cannot continue in the labour market through part-time employment while receiving partial retirement pension. Retirement is a full-time job.

For a comprehensive synopsis on retirement legislation changes in Portugal see Additional file 1: Appendix A in the web appendix to this paper. ${ }^{4}$

\section{Data}

The data used in the empirical analysis comes from a specific module of the Portuguese Labour Force Survey (Inquérito ao Emprego) called "Transition to Retirement". These data were collected by the Portuguese Statistics Office (INE) and they refer to the second quarter of 2006. The module was addressed to individuals aged 50 to 69 , inclusive, employed and non-employed. Non-employed individuals must have left the last job with 50 or more years of age. The aim of the module is to obtain exhaustive and comparable information on the transition from active life into retirement, in order to keep track of the progresses made in achieving the goals defined in the European Union towards promoting active ageing and postponing labour force exit.

Table 1 shows the sample values for the Labour Force Survey (second quarter of 2006) and the "Transition to Retirement" module.

Table 1 Sample values, Labour Force Survey (LFS) (second quarter 2006)

\begin{tabular}{lcccccc}
\hline & Total & \multicolumn{2}{c}{ Men } & & \multicolumn{2}{c}{ Women } \\
\cline { 3 - 4 } & & Total & $\%$ & & Total & $\%$ \\
\hline Individuals surveyed in the LFS & 45,166 & 21,584 & 47.79 & & 23,582 & 52.21 \\
Individuals aged 50 to 69 in the LFS & 11,685 & 5,439 & 46.55 & & 6,246 & 53.45 \\
Individuals surveyed in the module & 9,485 & 5,044 & 53.18 & & 4,441 & 46.82 \\
\hline
\end{tabular}

Source: Explanation document from the Labour Force Survey's 2006 module "Transition to Retirement", INE. 
Women represent more than half of the Labour Force Survey sample, and this is also the case for the subsample of individuals aged 50 to 69 . However, gender representation is reversed in the "Transition to Retirement" module, with men accounting for 53\% of the responses. Therefore, the module sample does not reproduce accurately the Labour Force Survey's gender composition.

From the initial sample we have excluded the military for they face a specific labour market (22 individuals), students (26 observations), and also unpaid household workers (371 observations - 99\% of which are women) or other inactive older individuals (507 observations) due to a fragile involvement in the labour market. Also, we left out the unemployed (236 observations) because their motivation towards the reduction in hours of work is naturally biased, since they want to increase their actual number of hours of work (and, therefore, may report the intention of no reduction in hours of work just because they are currently out of employment), and the self-employed (2871 observations) since they can more freely alter hours of work than employees.

The sample includes individuals with 15 or more years of work (80 observations deleted) because this is the minimum required number of years with payments to Social Security for a worker to become eligible for retirement benefits. Finally, miners and fishermen were also excluded (73 observations) since, due to the legally recognized weary nature of these occupations, they are subject to specific retirement legislation and may withdraw from the labour force before age $65 .{ }^{5}$ These exclusions led to the sample size depicted in Table 2.

The questionnaire of the "Transition to Retirement" module is presented in Additional file 1: Appendix B of the web appendix. Besides the variables collected through the questionnaire, the database includes additional information taken from the Labour Force Survey like gender, age, marital status, education, labour market situation (employed, unemployed, retired, home worker, student, other inactive) and nationality. For employed individuals it also presents information on the location, industry and size of the firm where they work and on the occupation, type of contract, date of admission into the firm, regime of work (part-time or full-time), hours of work and earnings. For those non-employed it shows the reason for leaving the last job, occupation held and the industry where he/she worked. Information on labour earnings before retirement is inexistent. Unfortunately, non-employed respondents were not asked about their labour income prior to retirement or unemployment. Also, the survey does not include any measure of the individual's wealth. This is regrettable since income and wealth are important determinants of the retirement decision (Hanoch and Honig 1983; Mitchell and Fields 1984; Dugan 1984; Ruhm 1990).

Table 2 Study sample

\begin{tabular}{llc}
\hline & \multicolumn{2}{c}{ Sample } \\
\cline { 2 - 3 } Labour market status & Total & $\%$ \\
\hline Employed & 3,319 & 62.94 \\
Retired $^{(1)}$ & 1,954 & 37.06 \\
Total & 5,273 & 100 \\
\hline
\end{tabular}

Source: Computations from the authors based on the "Transition to Retirement" module data, 2006. Portugal, National Statistics Office (INE) (2009), data from the Labour Force Survey in magnetic medium. Note: ${ }^{(1)}$ These have completely withdrawn from the labour force. 
Question 2 of the "Transition to Retirement" survey is the question of interest in this research: "Did you reduce or do you intend to reduce your working schedule before exiting the labour force?" The inquiry's instructions state that "exiting the labour force" means having no professional occupation with earnings as motivation, regardless of the legal retirement age. A summary of the possible answers is illustrated in Table 3 according to the individuals' labour market status. Answering "Yes, I have reduced it" means that the individual has intentionally reduced his/her working hours to prepare the exit from the labour force.

As Table 3 shows, one in five retirees has reduced hours of work before retirement. These individuals averaged 64 years of age in 2006 and 59 years old when they started collecting a retirement pension, which is clearly below the legal retirement age. Data additionally show that those who did and those who did not reduce hours of work present the same age averages; thus, one may start wondering about the efficacy of hours' reduction on postponing the exit from the labour force. Nevertheless, early retirement was very attractive in Portugal until 2005. Negligible penalties on pension benefits for those exiting the labour market before age 65 made early retirement very appealing. Hence, this sample feature of labour force withdrawal before reaching the legal retirement age may be explained by Social Security incentives.

As for employed older individuals, only a little more than $3 \%$ report a reduction in hours of work to prepare their exit from the labour force and their mean age is 59 years old. On average, these individuals are older than the ones who have not reduced their working hours.

Other two questions of relevance are: Question 3b "At what age do you intend to leave the labour force?" and Question 7b "At what age did you start collecting a retirement pension?" Question $3 \mathrm{~b}$ is addressed to individuals who are still in the labour force, in this case employed older individuals, while Question $7 \mathrm{~b}$ is directed both at people who might already be retired and at employed individuals. The mean intended age of retirement is 64 years old and 59 is the mean and median age of start of pension collection. Conditional on being in the labour force, employed individuals report a higher "expected" age of retirement when compared to the average age of retirement of retirees (64 versus 59 years old, respectively). Considering that in 2005 (see Additional file 1: Appendix A in the web appendix) a legal diploma suspended all early retirement schemes, making the collection of pension benefits only possible at age 65 or over, retirement expectations of active individuals are surely influenced.

Table 4 provides detailed descriptive statistics of the sample used in the empirical analysis by gender and labour force status. The average working career of Portuguese workers is considerably long. Retired individuals have worked for almost 40 years and they started collecting retirement pension benefits before age 60, on average. Women have shorter careers in the

Table 3 Working hours' reduction before retirement, by labour market status

\begin{tabular}{lcc}
\hline Hours' reduction (before retirement) & Employed & Retired $^{\text {(1) }}$ \\
\hline (a) Yes, I have reduced it & $3.25 \%$ & $20.98 \%$ \\
(b) No, but I intend to reduce it in the next 5 years & $11.96 \%$ & - \\
(c) No, and I have no intention to do so in the next 5 years/Did not reduce & $30.37 \%$ & $79.02 \%$ \\
(d) Will not reduce & $54.41 \%$ & - \\
Observations & 3,319 & 1,954
\end{tabular}

Source: Computations from the authors based on the "Transition to Retirement" module data, 2006. Portugal, National Statistics Office (INE) (2009), data from the Labour Force Survey in magnetic medium.

Note: ${ }^{(1)}$ Retired individuals that have answered "No, but intends to reduce it in the next 5 years" or "Won't reduce" were reclassified into the category "Did not reduce" for they are already out of the labour force. 
Table 4 Descriptive statistics, by gender and labour force status

\begin{tabular}{|c|c|c|c|c|c|c|c|c|c|}
\hline \multirow{2}{*}{$\begin{array}{l}\text { Variable } \\
\text { Labour force status }\end{array}$} & \multicolumn{3}{|c|}{ All } & \multicolumn{3}{|c|}{ Men } & \multicolumn{3}{|c|}{ Women } \\
\hline & All & Retired & Employed & All & Retired & Employed & All & Retired & Employed \\
\hline \multirow[t]{2}{*}{$A g e^{(1)}$} & 56.84 & 58.82 & 55.68 & 56.85 & 58.67 & 55.75 & 56.84 & 59.02 & 55.59 \\
\hline & (4.86) & $(4.72)$ & $(4.56)$ & $(4.82)$ & $(4.69)$ & $(4.56)$ & $(4.91)$ & $(4.74)$ & $(4.57)$ \\
\hline \multirow[t]{2}{*}{ Years of work ${ }^{(1)}$} & 37.95 & 39.60 & 36.98 & 39.30 & 40.81 & 38.39 & 36.35 & 38.11 & 35.33 \\
\hline & (7.93) & (7.95) & $(7.76)$ & $(7.20)$ & $(7.22)$ & (7.04) & (8.45) & $(8.53)$ & $(8.23)$ \\
\hline Reduction $^{(2)}$ (Yes) & 9.82 & 20.98 & 3.25 & 8.45 & 19.96 & 1.51 & 11.46 & 22.23 & 5.29 \\
\hline \multicolumn{10}{|l|}{ Activity sector } \\
\hline Agriculture & 5.59 & 7.37 & 4.55 & 5.17 & 4.92 & 5.31 & 6.10 & 10.38 & 3.66 \\
\hline Industrial & 28.43 & 31.83 & 26.42 & 37.52 & 39.00 & 36.63 & 17.61 & 23.03 & 14.50 \\
\hline Services & 65.98 & 60.80 & 69.03 & 57.31 & 56.08 & 58.05 & 76.29 & 66.59 & 81.84 \\
\hline Blue-collar & 54.45 & 53.89 & 54.78 & 59.23 & 55.15 & 61.69 & 48.75 & 52.34 & 46.70 \\
\hline \multicolumn{10}{|l|}{ Education } \\
\hline 0 years & 11.87 & 19.75 & 7.23 & 8.62 & 12.91 & 6.04 & 15.74 & 28.16 & 8.62 \\
\hline 4 years & 51.55 & 46.88 & 54.29 & 56.37 & 55.25 & 57.05 & 45.81 & 36.60 & 51.08 \\
\hline 6 years & 6.77 & 5.73 & 7.38 & 7.19 & 6.59 & 7.55 & 6.27 & 4.68 & 7.18 \\
\hline 9 years & 11.06 & 11.21 & 10.97 & 11.55 & 12.53 & 10.96 & 10.47 & 9.58 & 10.97 \\
\hline High school & 6.92 & 6.45 & 7.20 & 6.70 & 6.87 & 6.60 & 7.18 & 5.93 & 7.90 \\
\hline University & 11.83 & 9.98 & 12.93 & 9.56 & 5.85 & 11.80 & 14.53 & 15.05 & 14.24 \\
\hline \multicolumn{10}{|l|}{ Region } \\
\hline North & 24.50 & 22.72 & 24.83 & 25.55 & 24.88 & 25.95 & 22.26 & 20.07 & 23.51 \\
\hline Centre & 12.90 & 10.39 & 14.37 & 13.16 & 10.21 & 14.93 & 12.58 & 10.60 & 13.72 \\
\hline Lisbon & 22.57 & 25.74 & 20.70 & 21.40 & 26.18 & 18.51 & 23.96 & 25.20 & 23.25 \\
\hline Alentejo & 15.91 & 17.86 & 14.76 & 14.21 & 15.04 & 13.70 & 17.94 & 21.32 & 16.00 \\
\hline Algarve & 9.84 & 9.77 & 9.88 & 9.56 & 10.03 & 9.28 & 10.17 & 9.46 & 10.58 \\
\hline Azores & 6.96 & 7.47 & 6.66 & 8.48 & 8.82 & 8.28 & 5.15 & 5.82 & 4.77 \\
\hline Madeira & 7.78 & 6.04 & 8.80 & 7.64 & 4.83 & 9.34 & 7.93 & 7.53 & 8.16 \\
\hline Active spouse (3) $^{(3)}$ & 62.58 & 23.45 & 85.94 & 67.73 & 39.62 & 87.86 & 59.48 & 11.74 & 84.91 \\
\hline Observations & 5,273 & 1,954 & 3,319 & 2,865 & 1,077 & 1,788 & 2,408 & 877 & 1,531 \\
\hline
\end{tabular}

Source: Computations from the authors based on the "Transition to Retirement" module data, 2006. Portugal, National Statistics Office (INE) (2009), data from the Labour Force Survey in magnetic medium.

Notes: For retired individuals, the variable Age refers to the age of start of pension benefits' receipt. ${ }^{(1)}$ Continuous variables: standard deviations are presented in parenthesis. All other variables are dummies and values reported are percentages. ${ }^{(2)}$ Answers (b), (c) and (d) of Question 2 were gathered into a single category "Did not reduce". ${ }^{(3)}$ There are 2,670 observations for the variable Active spouse.

labour force but they retire at slightly later ages than men. Overall, Table 4 also shows that a reduction of hours of work is not very common in the Portuguese labour market: less than $10 \%{ }^{6}$ of the individuals report a reduction in hours of work as a way of gradual retirement. Women reduce hours of work to a greater extent than men, and this difference is more pronounced for those still in the labour force (i.e., employed).

Almost two thirds of the individuals in the sample work in Services, which is also the activity sector where a reduction in hours of work before retirement is more prevalent, both for men and women. For $54 \%$ of the individuals the occupation held was classified as bluecollar. The definitions of blue/white collar and the industries included in each of the activity sectors are presented in Additional file 1: Appendix C in the web appendix (Tables $\mathrm{C} 1$ and $\mathrm{C} 2$ ). 
The sample is characterized by low educational levels: more than $60 \%$ of the individuals have 4 or less years of school attainment. This feature of the sample is not surprising given the age range of the individuals, 50 to 69 years old (which means that they were born between 1937 and 1964) and the fact that until 1986 mandatory schooling in Portugal comprised just 6 years. ${ }^{7}$ However, almost 12\% of the individuals show higher education attainment, with women reporting a higher incidence of this higher educational level.

A worker's participation in the labour force may be modelled using survival analysis where survival is interpreted as the presence in the labour market. The use of survival analysis techniques to describe the data, which is done in Figure 1, shows that, as expected, the cumulative hazard ${ }^{8}$ in Figure 1 is rising with age at an increasing rate and it faces a considerable increase at age $65 .{ }^{9}$

Relating the Age of exit from the labour force with the Reduction variable, Figure 2 plots the survival function by reduction status (that is, if the individual reduced or not his/her hours of work) and gender. It shows that those with a reduction in hours are more likely to exit the labour market at earlier ages. ${ }^{10}$ This is true for both men and women, but the difference in survival times by reduction status is higher for men than for women.

\section{Econometric setup}

\subsection{Transition data models: a parametric approach}

Transition or duration analysis models the length of time spent in a given state (for instance, in the labour force) before transition to another state (e.g. retired). The time of transition to retirement is called "failure time". A "state" is a qualitative characteristic of an individual at a specific point in time, "transition" is the change from one state to another, and a "spell" length or duration is the time spent in a given state.

In the empirical analysis there are two possible states a person can be in: active (in the labour force) or retired (out of the labour force). By failure time we mean the age of retirement (the age of exit from the labour force). The hazard rate is defined as the probability that retirement will occur at a particular age to an individual, given that the individual is at risk (i.e. in the labour force) at that age. The hazard is an unobserved variable, but it controls both the occurrence and the timing of events (or state transitions). Therefore, it is the fundamental dependent variable in transition data models. If the hazard is known to depend strongly on

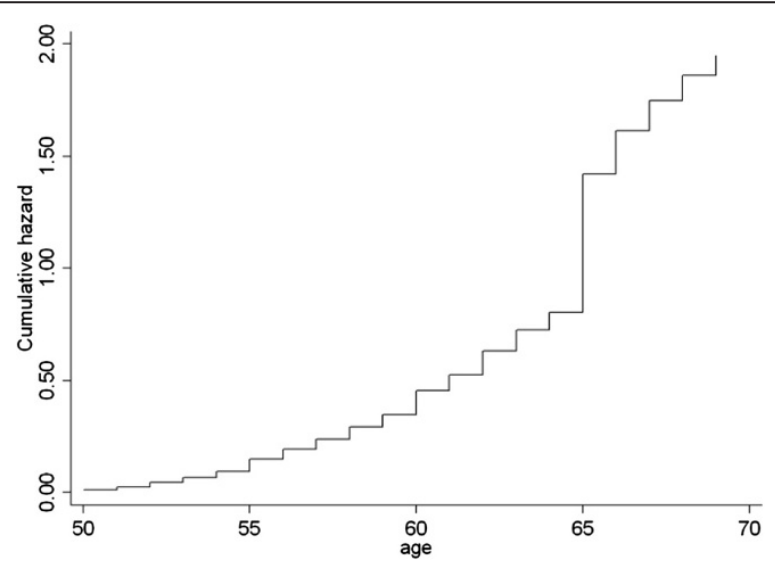

Figure 1 Nelson-Aalen cumulative hazard estimates. Source: Computations from the authors based on the "Transition to Retirement" module data, 2006. 


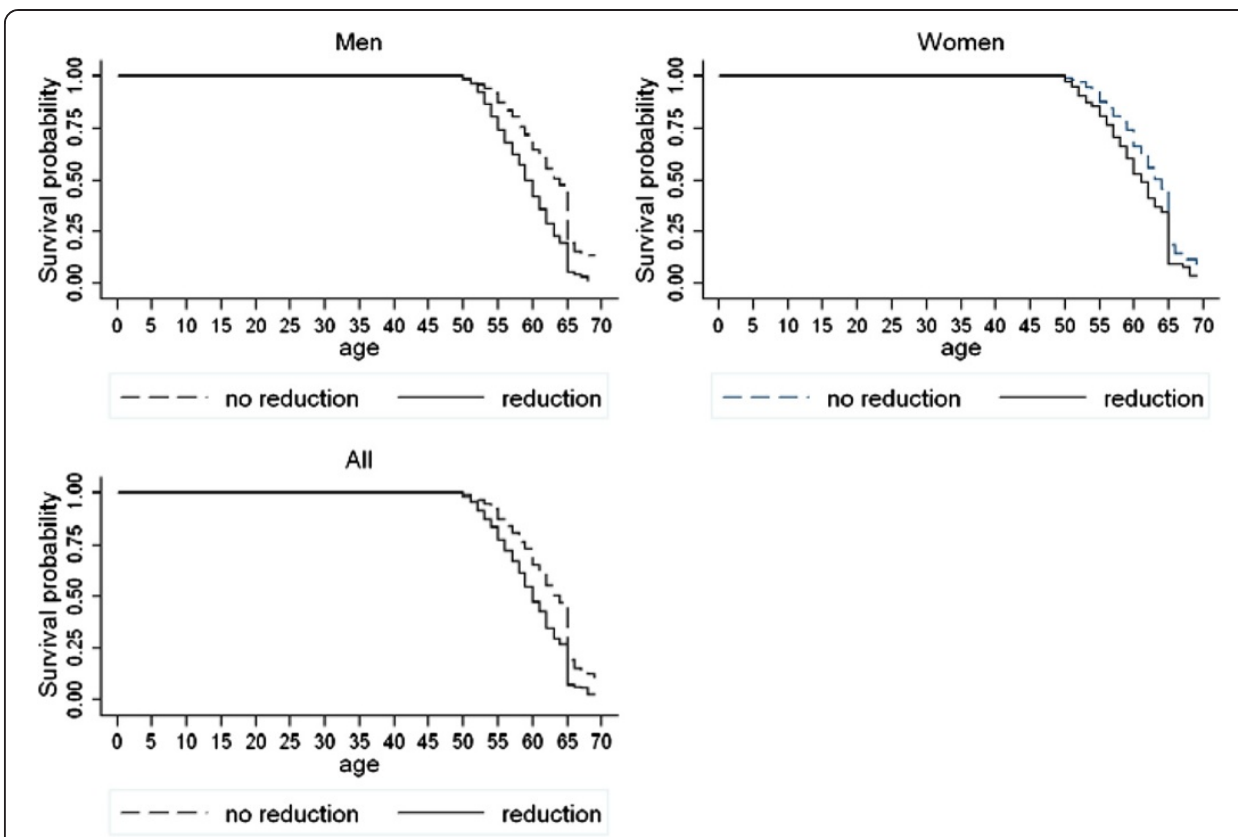

Figure 2 Kaplan-Meier survival function estimates, by reduction status and gender. Source: Computations from the authors based on the "Transition to Retirement" module data, 2006.

age but only weakly on time since other starting point (the date of entry in the labour force), then age is the most appropriate way to define the time scale (Allison 1984).

Due to the nature of the data used, some individuals are already in the initial state (thus we do not observe the date of entry into the labour market). This is relevant for the definition of the "spell". With age as the time scale and because the starting times are not observed, the spell is the duration of an individual's life until retirement. From now on we will call this duration a "spell of activity" (although it does not measure the number of working years).

We assume that, once an individual leaves the initial state (becomes retired), he/she remains in inactivity (that is, there is no reversed retirement; individuals do not come back to the labour force after retirement) which is not a very strong assumption considering that, according to the European Commission (2007), more than $99 \%$ of the people that were inactive in a given year remain inactive in the following year.

Transition or survival data are usually censored since some spells are incompletely observed. A complete spell of activity can be seen for retirees but for subjects that are still in the labour force we do not observe the complete spell of activity. That means that data are right-censored or censored from above. Censoring is the main reason for modelling transitions instead of the mean duration as weaker distributional assumptions are needed to obtain consistent estimates (Cameron and Trivedi 2005).

A Weibull parametric regression model is used to study the effect of a reduction in hours of work on the age until which a person remains in the labour force. The Weibull has a hazard function given by $\lambda(t)=\gamma \alpha t^{\alpha-1}, 11$ where $\gamma$ is the hazard rate, $\alpha$ is a shape parameter indicating the monotonicity of the function and $t$ is a time variable. The hazard function will be monotonically increasing if $\alpha>1$ and monotonically decreasing if $\alpha<1$. The Weibull distribution assumes that $\gamma>0$ and $\alpha>0$. In other words, it considers a hazard that it is not constant over time. 
Estimation of the Weibull model is made by maximum likelihood. Following Cameron and Trivedi (2005), with censored data the observed survival time $t$ is the age at an incomplete spell, and the data are augmented by a censoring indicator variable. For right-censored observations it is known that the age of retirement exceeded $t$ so the contribution to the likelihood is

$$
\operatorname{Pr}[T>t]=\int_{t}^{\infty} f(u \mid \mathbf{x}, \boldsymbol{\theta}) d u=1-F(t \mid \mathbf{x}, \boldsymbol{\theta})=S(t \mid \mathbf{x}, \boldsymbol{\theta})
$$

where $T$ denotes the age of retirement without censoring, $\mathbf{x}$ are regressors that can vary across individuals but do not vary over a spell for a given individual and $\boldsymbol{\theta}$ is a $q \times 1$ parameter vector. $S($.) represents the survivor function.

The conditional density for the $i$ th observation is $f\left(t_{i} \mid \mathbf{x}_{i}, \boldsymbol{\theta}\right)^{\delta i} \mathrm{~S}\left(t_{i} \mid \mathbf{x}_{i}, \boldsymbol{\theta}\right)^{1-\delta i}$, where $\delta_{i}$ is a right-censoring indicator with

$$
\delta_{i}=\left\{\begin{array}{l}
1, \text { if complete spell (no censoring) } \\
0, \text { if incomplete spell (right censoring) }
\end{array}\right.
$$

Taking logs and summing, assuming independence over $i$, the maximum likelihood estimator $\hat{\boldsymbol{\theta}}$ maximizes the likelihood function

$$
\ln L(\boldsymbol{\theta})=\sum_{i=1}^{N}\left[\delta_{i} \ln f\left(t_{i} \mid \mathbf{x}_{i}, \boldsymbol{\theta}\right)+\left(1-\delta_{i}\right) \ln S\left(t_{i} \mid \mathbf{x}_{i}, \boldsymbol{\theta}\right)\right]
$$

In the Weibull model, regressors are usually introduced by letting $\gamma=\exp \left(\mathbf{x}^{\prime} \boldsymbol{\beta}\right)$, ensuring that $\gamma>0$ while $\alpha$, the shape parameter, does not vary with regressors. Then,

$$
\ln f(t \mid \mathbf{x}, \boldsymbol{\beta}, \alpha)=\ln \left[\exp \left(\mathbf{x}^{\prime} \boldsymbol{\beta}\right) \alpha t^{\alpha-1} \exp \left(-\exp \left(\mathbf{x}^{\prime} \boldsymbol{\beta}\right) t^{\alpha}\right)\right]=\mathbf{x}^{\prime} \boldsymbol{\beta}+\ln \alpha+(\alpha-1) \ln t-\exp \left(\mathbf{x}^{\prime} \boldsymbol{\beta}\right) t^{\alpha}
$$

and

$$
\ln S(t \mid \mathbf{x}, \boldsymbol{\beta}, \alpha)=\ln \left[\exp \left(-\exp \left(\mathbf{x}^{\prime} \boldsymbol{\beta}\right) t^{\alpha}\right)\right]=-\exp \left(\mathbf{x}^{\prime} \boldsymbol{\beta}\right) t^{\alpha}
$$

Then, the likelihood function in (2) becomes

$$
\ln L=\sum_{i}\left[\delta_{i}\left\{\mathbf{x}^{\prime}{ }_{i} \boldsymbol{\beta}+\ln \alpha+(\alpha-1) \ln t_{i}-\exp \left(\mathbf{x}^{\prime}{ }_{i} \boldsymbol{\beta}\right) t_{i}^{\alpha}\right\}-\left(1-\delta_{i}\right) \exp \left(\mathbf{x}^{\prime}{ }_{i} \boldsymbol{\beta}\right) t_{i}^{\alpha}\right] .
$$

The key policy variable in the model is the reduction of hours on work before retirement and its impact on the retirement hazard is of relevance for this analysis.

\subsection{Variables used in the estimation}

Working hours' reduction is the explanatory variable of interest in the model. Question 2 of the survey allows four possible answers (see Table 3). We consider answers (c) and (d) as being the same for those employed, meaning that they will not reduce hours of work before exiting the labour force. The main issue is how to treat the workers' 'intentions of reduction' (answer (b)). For retirees this problem does not arise since they either reduced or did not reduce their hours of work before leaving the labour market. As for employed individuals the treatment is not as straightforward.

Nevertheless, in order to explore this variable we use two different classifications for it. First, we consider just the actions that have occurred so far, that is, treat the intentions as non-actions. We therefore construct a variable called Reduction $A$ which equals 0 if the 
person did not/will not reduce hours of work or if he/she intends to do so, and 1 if the individual has already reduced. If, however, intentions can predict future actions, treating intentions as actions might be useful to study the influence of an action (reduction in hours of work) on an outcome (labour force participation) when the specific action has not yet occurred. The study of intentions and subsequent behaviour is a subject of relevance in Psychology. The theory of reasoned action (Ajzen and Fishbein 1980; ${ }^{12}$ Fishbein and Ajzen 1975) postulates that a person's intention to engage in behaviour is the immediate determinant of that behaviour. In other words, people are expected to behave in accordance with their intentions. Evidence also provides support to the theory by showing high correlations between intentions and actual behaviour that range from 0.72 to 0.90 (Ajzen 2005). In the light of this theory, and as a second alternative, we treat reported intention of reducing hours of work as an action in order to study its effect on the elderly 'survival' in the labour force. The resulting variable is Reduction $B$ which is equal to 0 if the person will not reduce hours of work and 1 if the individual did reduce or intends to do so. We expect that using these alternative Reduction variables will enable us to see how sensitive the age of exit from the labour force is to the assumptions made for the variable of interest.

Age is the analysis time variable and it refers to the actual age for the people that are still active (incomplete spells) but, for retired individuals (complete spells), it is the age of retirement. We use the age at which the individual started receiving a retirement pension as a proxy for the age of retirement, since the survey does not ask when he/she actually withdrew from the labour force (the retirement age) but it asks the age he/she started collecting a pension. ${ }^{13}$ This is done in order to capture the approximate moment of failure (exit) for retirees. Also, in Question $3 \mathrm{~b}^{14}$ of the survey people report the age at which they intend to retire and this age intention is used as the analysis time variable for employed subjects when using the Reduction $B$ as the covariate of interest.

Another limitation as a consequence of the questionnaire's design is that it is not possible to know when the reduction started (close or far from the effective age of exit) or the amount of hours reduced (for example, if the worker made a transition from full-time to part-time employment, or if it was just a 1 hour reduction). Such information would contribute to the enrichment of the analysis.

Besides the Reduction variable we also include in the model regressors like gender, activity sector, type of occupation, education and region of residence. Additionally, for married (or living with a partner) people we include the spouse/partner labour force status (active or retired). Table 5 shows some descriptive statistics of the variables used.

There are $37 \%$ of failures (retirees) in the sample which means that the rest of the observations in the sample are censored.

The overall sample is also characterized by low educational levels. Younger individuals are more educated than older ones. Indeed, only $5 \%$ of the individuals aged 65 to 69 have a university degree, against $8 \%, 13 \%$ and $15 \%$ for those in the age groups $60-64,55-59$ and 50-54, respectively. Women are overrepresented both at the bottom (0 years) and at the top (university) of the education ladder, and more than $3 / 4$ work in the Services. Also, women reduce hours of work more often than men. Table 6 provides additional labour market statistics concerning hours of work, activity sector and gender. It shows that women work fewer hours than men regardless of the activity sector.

Finally, from Table 5, both the likelihood of retirement and the probability of reducing hours of work rise with age. 
Table 5 Definition of the variables and mean characteristics

\begin{tabular}{|c|c|c|c|c|}
\hline \multirow[t]{2}{*}{ Variable } & \multirow[t]{2}{*}{ Definition } & \multicolumn{3}{|c|}{ Mean or percentage } \\
\hline & & All & Men & Women \\
\hline \multirow[t]{2}{*}{ Age (time) } & \multirow{2}{*}{$\begin{array}{l}\text { Person's age if employed or, if retired, the age of start of } \\
\text { pension receipt }\end{array}$} & 56.84 & 58.66 & 58.59 \\
\hline & & $(4.86)^{(1)}$ & $(5.85)^{(1)}$ & $(5.96)^{(1)}$ \\
\hline Retired (failure) & $=1$ if the person already exit the labour force & 37.06 & 37.59 & 36.42 \\
\hline Reduction A & $=1$ if the individual has effectively reduced his/her hours of work & 9.82 & 8.45 & 11.46 \\
\hline Reduction $B^{(2)}$ & $=1$ if the individual did reduce or intends to reduce hours of work & 20.12 & 19.20 & 21.21 \\
\hline Male & $=1$ if the person is of male gender & 54.33 & - & - \\
\hline \multicolumn{5}{|l|}{ Activity sector } \\
\hline Agriculture & $=1$ if the person works or worked in the agriculture sector & 5.59 & 5.17 & 6.10 \\
\hline Industrial & $=2$ if the person works or worked in the industrial sector & 28.43 & 37.52 & 17.61 \\
\hline Services & $\begin{array}{l}=3 \text { if the person works or worked in the services sector } \\
\text { (omitted category) }\end{array}$ & 65.98 & 57.31 & 76.29 \\
\hline Blue-collar & $\begin{array}{l}=1 \text { if the individual works or has worked in an occupation } \\
\text { classified as blue-collar }\end{array}$ & 54.45 & 59.23 & 48.75 \\
\hline \multicolumn{5}{|l|}{ Education } \\
\hline 0 years & $=1$ if the person has no complete degree of education & 11.87 & 8.62 & 15.74 \\
\hline 4 years & $=2$ if the person completed 4 years of education & 51.55 & 56.37 & 45.81 \\
\hline 6 years & $=3$ if the person completed 6 years of education & 6.77 & 7.19 & 6.27 \\
\hline 9 years & $=4$ if the person completed 9 years of education & 11.06 & 11.55 & 10.47 \\
\hline High school & $=5$ if the person has a high-school diploma & 6.92 & 6.70 & 7.18 \\
\hline University & $=6$ if college degree & 11.83 & 9.52 & 14.53 \\
\hline \multicolumn{5}{|l|}{ Region } \\
\hline North & $\begin{array}{l}=1 \text { if the person resides in the North of Portugal } \\
\text { (omitted category) }\end{array}$ & 24.05 & 25.55 & 22.26 \\
\hline Centre & $=2$ if the person resides in the Centre & 12.90 & 13.16 & 12.58 \\
\hline Lisbon & $=3$ if resides in Lisbon & 22.57 & 21.40 & 23.96 \\
\hline Alentejo & $=4$ if he/she resides in Alentejo & 15.91 & 14.21 & 17.94 \\
\hline Algarve & $=5$ if he/she resides in Algarve & 9.84 & 9.56 & 10.17 \\
\hline Azores & $=6$ if he/she resides in Azores & 6.96 & 8.48 & 5.15 \\
\hline Madeira & $=7$ if he/she resides in Madeira & 7.78 & 7.64 & 7.93 \\
\hline Active spouse $^{(3)}$ & $=1$ if the spouse is still in activity & 62.58 & 67.73 & 59.48 \\
\hline
\end{tabular}

Source: Computations from the authors based on the "Transition to Retirement" module data, 2006. Portugal, National Statistics Office (INE) (2009), data from the Labour Force Survey in magnetic medium.

Note: ${ }^{(1)}$ Standard deviation of the variable Age; ${ }^{(2)}$ There are 2,738 observations for this variable; ${ }^{(3)}$ There are 2,670 observations for the variable Active spouse. Number of observations: 5,273.

\section{Results}

Tables 7 and 8 present the results for the Weibull model in the presence of censoring. Estimates on the Weibull parameter $\alpha$ suggest that the hazard is increasing over time $\alpha>1$, at an increasing rate $(\alpha>2){ }^{15}$

Moreover, despite the assumptions made for the Reduction variable, results remain unchanged: the reduction of hours of work before leaving the labour market shortens an individual's presence in the labour force. In fact, in Table 7 the coefficient on Reduction A at column (1) suggests that reducing hours of work increases the hazard rate by $61 \%$ compared to the subjects that did not reduce hours of work. Gielen (2009) finds that working hours flexibility have a positive effect on labour force participation of older women, but increasing working hours flexibility has little effect on raising older workers' total labour supply. 
Table 6 Distribution of employed population by regular hours of work, activity sector and gender (second quarter, 2006)

\begin{tabular}{|c|c|c|c|c|c|c|c|c|c|c|c|c|}
\hline \multirow{3}{*}{$\begin{array}{l}\text { Regular } \\
\text { hours } \\
\text { of work }\end{array}$} & \multicolumn{12}{|c|}{ Activity sector } \\
\hline & \multicolumn{3}{|c|}{ Agriculture } & \multicolumn{3}{|c|}{ Industrial } & \multicolumn{3}{|c|}{ Services } & \multicolumn{3}{|c|}{ Total } \\
\hline & All & Men & Women & All & Men & Women & All & Men & Women & All & Men & Women \\
\hline $1-10$ & 10.39 & 6.85 & 14.10 & 0.43 & 0.36 & 0.62 & 1.31 & 0.49 & 1.99 & 2.12 & 1.16 & 3.26 \\
\hline $11-30$ & 39.12 & 35.58 & 42.85 & 2.56 & 1.75 & 4.57 & 8.38 & 4.59 & 11.52 & 10.26 & 6.94 & 14.15 \\
\hline $31-35$ & 1.90 & 2.06 & 1.73 & 1.40 & 1.11 & 2.12 & 22.02 & 17.43 & 25.82 & 13.37 & 9.13 & 18.34 \\
\hline $36-40$ & 20.39 & 23.52 & 17.11 & 79.18 & 77.12 & 84.34 & 48.67 & 52.10 & 45.82 & 54.58 & 58.95 & 49.82 \\
\hline 41 or more & 25.20 & 29.10 & 21.11 & 15.54 & 18.60 & 7.83 & 18.83 & 24.20 & 14.37 & 18.58 & 22.51 & 14.37 \\
\hline
\end{tabular}

Nevertheless, Gielen (2009) considers that increasing the legal retirement age would be more effective in raising older workers' labour force participation and concludes that working hours' flexibility may not be a suitable instrument to improve older workers' labour supply. Using simulations, Gustman and Steinmeier (2004) suggest that if firms allowed partial retirement at the same hourly wage, this would impact retirement outcomes: partial retirement would increase from $30 \%$ to $67 \%$. When there is no restriction in partial retirement, the percentage completely retired declines by 4.7 to 14.1 percentage points at each year of age between 58 and 65 . Additionally, the number fully retired falls by 15.3 and 13.8 percentage points, respectively, for ages 67 and 69. Nevertheless, half the increase in partial retirement

Table 7 Weibull regression coefficients using Reduction $A$

\begin{tabular}{|c|c|c|c|c|c|}
\hline Variable & $\begin{array}{l}\text { All } \\
(1)\end{array}$ & $\begin{array}{l}\text { All } \\
(2)\end{array}$ & $\begin{array}{l}\text { All } \\
(3)\end{array}$ & $\begin{array}{c}\text { Men } \\
(4)\end{array}$ & $\begin{array}{c}\text { Women } \\
\text { (5) }\end{array}$ \\
\hline \multirow[t]{2}{*}{ Reduction A } & $0.477^{* * *}$ & $0.330^{* * *}$ & $0.343^{* * *}$ & $0.637^{* * *}$ & $0.330^{* * *}$ \\
\hline & $(0.057)$ & $(0.079)$ & $(0.082)$ & $(0.080)$ & $(0.083)$ \\
\hline \multirow[t]{2}{*}{ Male } & 0.018 & 0.068 & -0.036 & - & - \\
\hline & $(0.049)$ & $(0.069)$ & $(0.054)$ & & \\
\hline \multirow[t]{2}{*}{ Reduction $A \times$ Male } & - & - & $0.265^{* *}$ & - & - \\
\hline & & & $(0.112)$ & & \\
\hline \multicolumn{6}{|l|}{ Activity sector } \\
\hline \multirow[t]{2}{*}{ Agriculture } & 0.018 & 0.020 & 0.012 & $-0.397^{* * *}$ & $0.359^{* * *}$ \\
\hline & $(0.098)$ & $(0.133)$ & $(0.098)$ & $(0.153)$ & $(0.133)$ \\
\hline \multirow[t]{2}{*}{ Industrial } & $0.255^{* * *}$ & $0.291^{* * *}$ & $0.248^{* * *}$ & 0.026 & $0.620^{* * *}$ \\
\hline & $(0.056)$ & $(0.082)$ & $(0.056)$ & $(0.072)$ & $(0.088)$ \\
\hline \multirow[t]{2}{*}{ Blue-collar } & $-0.330^{* * *}$ & $-0.331^{* * *}$ & $-0.324^{* * *}$ & $-0.437^{* * *}$ & -0.154 \\
\hline & $(0.062)$ & $(0.094)$ & $(0.062)$ & $(0.079)$ & $(0.102)$ \\
\hline \multirow[t]{2}{*}{ Active spouse } & - & $-0.886^{* * *}$ & - & - & - \\
\hline & & $(0.077)$ & & & \\
\hline \multirow[t]{2}{*}{$a$} & 15.749 & 15.615 & 15.760 & 15.475 & 16.275 \\
\hline & $(0.251)$ & $(0.365)$ & $(0.251)$ & $(0.334)$ & $(0.383)$ \\
\hline Observations & 5,273 & 2,670 & 5,273 & 2,865 & 2,408 \\
\hline Log likelihood & $1,000.678$ & 629.093 & $1,003.460$ & 556.010 & 494.336 \\
\hline
\end{tabular}

Source: Computations from the authors based on the "Transition to Retirement" module data, 2006. Portugal, National Statistics Office (INE) (2009), data from the Labour Force Survey in magnetic medium.

Note: Standard errors are presented in parentheses. ${ }^{* *} /{ }^{* *} /{ }^{*}$ means significance at $1 \% / 5 \% / 10 \%$ level, respectively. All models have Education and Region dummies. 
Table 8 Weibull regression coefficients using Reduction B

\begin{tabular}{lcccc}
\hline Variable & All & All & Men & Women \\
& $(\mathbf{1})$ & $\mathbf{( 2 )}$ & $\mathbf{( 3 )}$ & $\mathbf{( 4 )}$ \\
\hline Reduction B & $0.124^{* * *}$ & $0.145^{* *}$ & $0.133^{* *}$ & $0.162^{* *}$ \\
Male & $(0.048)$ & $(0.070)$ & $(0.067)$ & $(0.070)$ \\
Reduction B $\times$ Male & 0.033 & 0.041 & - & - \\
& $(0.041)$ & $(0.045)$ & & - \\
Activity sector & - & -0.041 & - & \\
Agriculture & & $(0.096)$ & & 0.101 \\
& & & $-0.224^{*}$ & $(0.117)$ \\
Industrial & -0.026 & -0.026 & $(0.126)$ & $0.316^{* * *}$ \\
& $(0.084)$ & $(0.084)$ & -0.012 & $(0.078)$ \\
Blue-collar & $0.098^{* *}$ & $0.099^{* *}$ & $(0.061)$ & -0.099 \\
& $(0.048)$ & $(0.048)$ & $-0.402^{* * *}$ & $(0.083)$ \\
a & $-0.277^{* * *}$ & $-0.277^{* * *}$ & $(0.069)$ & 15.686 \\
& $(0.053)$ & $(0.053)$ & 15.170 & $(0.355)$ \\
Observations & 15.290 & 15.290 & $(0.315)$ & 1,254 \\
Log likelihood & $(0.203)$ & $(0.234)$ & 1,484 & $1,462.922$ \\
\hline
\end{tabular}

Source: Computations from the authors based on the "Transition to Retirement" module data, 2006. Portugal, National Statistics Office (INE) (2009), data from the Labour Force Survey in magnetic medium.

Note: Standard errors are presented in parentheses. ${ }^{* * * * *} / *$ means significance at $1 \% / 5 \% / 10 \%$ level, respectively. All models have Education and Region dummies.

comes from full-time work, reducing total hours of work. The authors conclude that, among those aged 62 to 69 who have a long term commitment to the labour market, the flexibility in hours of work would contribute to reduce by 10 to 15 percentage points the fraction completely retired. Partial retirement in that age group would increase by 20 percentage points. If hours' constraints were abolished, partial retirement would increase significantly but full-time employment and full-time retirement would reduce, resulting in a small net increase in full-time equivalent employment. This suggests that working hours' flexibility plays a marginal role in the expansion of overall older workers' labour force participation. ${ }^{16}$

The variable Reduction that we use is more limited and less informative than the approaches used in the literature. We use only an indicator variable and other studies use hours of work to assess the reduction. Additionally, these studies take advantage of longitudinal data while we use cross-sectional data. Also, previous literature focuses on the labour force participation and not on the age of retirement.

One may wonder if the reduction of hours of work was the result of the will of the worker or if it was initiated by the employer. In the eminence of a layoff firms often reduce hours of work before permanent shutdown and the reduction of working time could be capturing this effect. Nevertheless, considering just the subsample of retirees, looking at the reason for retirement (Question T10 of the survey) it is possible to see that only 1.5\% of the retirees reporting a reduction in hours of work before retirement answer "job loss" as the reason for retirement. Therefore, the fear of a potential endogeneity problem can be mitigated.

Figure 3 clearly shows that the hazard of retirement increases with age at an increasing rate and that it is higher for individuals that reduced hours of work. The same pattern is 


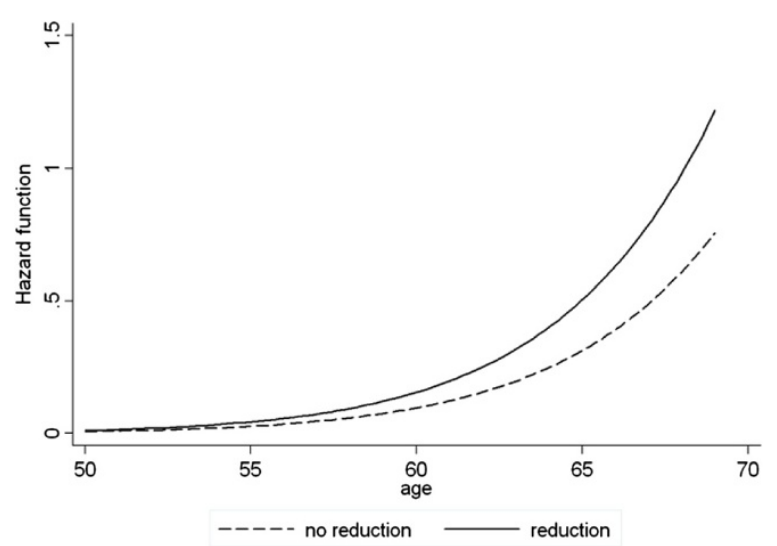

Figure 3 Retirement hazard, by reduction status (Reduction A). Source: Computations from the authors based on the "Transition to Retirement" module data, 2006.

obviously reflected in the survival curve in Figure 4. Those that do not reduce working time on average stay longer in the labour market.

The coefficients for the Blue-collar variable are negative and quite similar through columns (1) to (3), Table 7. The coefficient in column (1) shows that blue-collar workers experience a hazard rate that is only $72 \%$ of the hazard for white-collar workers. This result is consistent with the findings of Dorn and Sousa-Poza (2005). However, this result may be capturing an income effect. In the absence of income and wealth variables, since blue-collar occupations are associated with lower earnings, that result may hint on the fact that individuals with lower wages retire at later ages.

Looking at column (2) in Table 7, for those who are married or live with a partner, having a wife/husband that is still in the labour force reduces the retirement hazard. Effectively, the hazard of retirement for those who have an active spouse is just $41 \%$ of the hazard for those who have a spouse who is already out of the labour force. Dorn and Sousa-Poza (2005) and Johnson et al. (2000) present similar findings. The former authors conclude that the odds of retiring early are $44 \%$ higher for those with a non-active partner. While the latter find that individuals were less likely to retire if their spouses were still working than if their spouses were already retired.

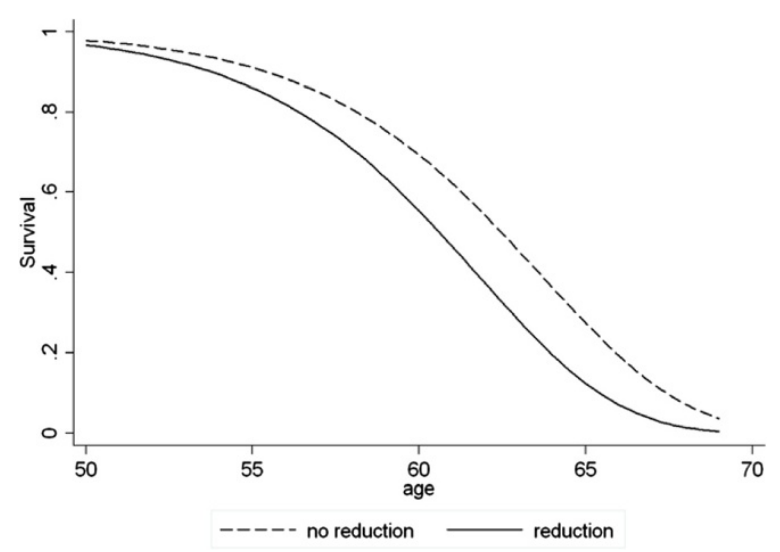

Figure 4 Survival curve, by reduction status (Reduction A). Source: Computations from the authors based on the "Transition to Retirement" module data, 2006. 
The variable Male shows no statistical significance, which means that there is no difference in the retirement hazard between men and women. Also, those working in the industrial sector face a 34\% higher hazard than those working in services.

Column (3) introduces an interaction term between the Reduction variable and gender. Results show that those who reduce hours of work face a hazard $41 \%$ higher than those who do not reduce hours. Additionally, men who reduce hours of work increase the hazard of retirement by $30 \%$.

Dividing the sample by gender, separate estimates for men and women are presented in columns (4) and (5) of Table 7. Both for men and women, a reduction in hours of work before retirement is associated with a higher retirement hazard. A Chow test ${ }^{17}$ performed on these models rejects the null hypothesis of the equality of coefficients between men and women. Also, for a 95\% confidence level, the difference between the gender coefficients on the Reduction A variable is statistically significant. For the Swiss case, Dorn and Sousa-Poza (2005) find that men are more likely to retire earlier than women. There are statistical differences in the explanatory power of the covariates for men and women. For men, the retirement hazard of those who reduced hours of work compared to those who did not (1.89) is 60 percentage points higher than the hazard obtained for women (1.39). The interaction term estimate in column (3), Table 7, highlights the above reported difference in the hazard for men and women, between those who reduced hours of work and those who did not.

Comparing columns (4) and (5) in Table 7 we find relevant gender differences concerning the impact of the variable Activity sector on the hazard. Effectively, men employed in agriculture experience a retirement hazard that is only $67 \%$ of the hazard for men that work in services. There are no differences in the hazard between men employed in services and those in the industrial sector. However, for women, the effect is quite the opposite: women in agriculture and in the industrial sectors face, respectively, a $43 \%$ and $85 \%$ higher hazard than women employed in services. It seems that being employed in services is associated with retirement at earlier ages for men while, for women, working in services delays retirement. Because work in agriculture and in the industrial sectors is more physically demanding, women may want to exit the labour force earlier. The impact of the variable Blue-collar is also different between genders. Men in blue-collar occupations have a smaller retirement hazard compared to men in white-collar occupations (the hazard for blue-collars is only $65 \%$ of the retirement hazard for white-collar men). Since wages are particularly low in blue-collar occupations, these workers probably do not have the financial support needed to exit the labour force at early ages. As for women, there are no statistical differences between the hazards experienced by female employees in white or bluecollar occupations.

Treating intentions as the best predictor of future actions, Table 8 reports the same effect of the Reduction variable on the retirement hazard as in the previous analysis.

From Table 8, column (1), those who have reduced hours of work before leaving the labour market face a 13\% higher hazard of retirement than those who did not. Again, it indicates that the reduction in working hours is associated with retirement at earlier ages.

When intentions are treated as effective actions (Reduction B, Table 8) the retirement hazard declines by 48 percentage points compared to the hazard in column (1) of Table 7 (Reduction A), but it is still higher for those who reduced hours of work. 
Figure 5 reveals that the hazard of retirement increases with age at an increasing rate and that it is higher for individuals that reduced hours of work. The survival curve in Figure 6 shows that those who do not reduce working time on average stay longer in the labour market.

Therefore, it seems that working hours' flexibility will have no effect in expanding older workers' labour force participation. Those who reduce hours of work leave activity earlier than those who do not. ${ }^{18}$ As Gielen (2009) suggests, other instruments, like the increase in the legal retirement age, seem to be more effective in delaying the exit from the labour market.

Like in Table 7 columns (3) and (4), Table 8, show separate estimates by gender. Once again, a Chow test ${ }^{19}$ performed on these models rejects the null hypothesis of the equality of coefficients between men and women. However, in this sample, the gender difference for the Reduction $B$ is not statistically different from zero (Chi-squared $=0.09$ and $\mathrm{p}$-value $=$ 0.7634). This is in accordance with the statistical significance of the coefficient of the interaction term.

As in Table 7, being employed in the industrial sector reduces the likelihood of remaining in activity: columns (1) and (2) in Table 8 suggest that the hazard of retirement is $10 \%$ higher for those working in the industrial sector compared to those employed in services. However, the coefficients on this variable are smaller in Table 8; in fact, the hazard is reduced by $18-19$ percentage points ${ }^{20}$ when considering Reduction $B$ rather than Reduction $A$. Once again, this difference is mainly due to women.

The evidence discussed so far indicates that a reduction in hours of work before retirement seems to be associated with retirement at earlier ages. ${ }^{21}$ In fact, when asked (Question 4 of the survey) if working hours' flexibility would work as an incentive to expand labour force participation, more than $90 \%$ of the elderly responded negatively.

\section{Conclusions}

Portuguese older workers (55-64 years) present high activity and employment rates (54\% and 51\%, respectively), above the European Union (EU25) average and already above the $50 \%$ threshold for the employment rate to be achieved in EU countries by 2010 (European Commission 2008). Table 4 in section 3 shows a strong link between older workers and the labour market: current and past working careers average above 35 years.

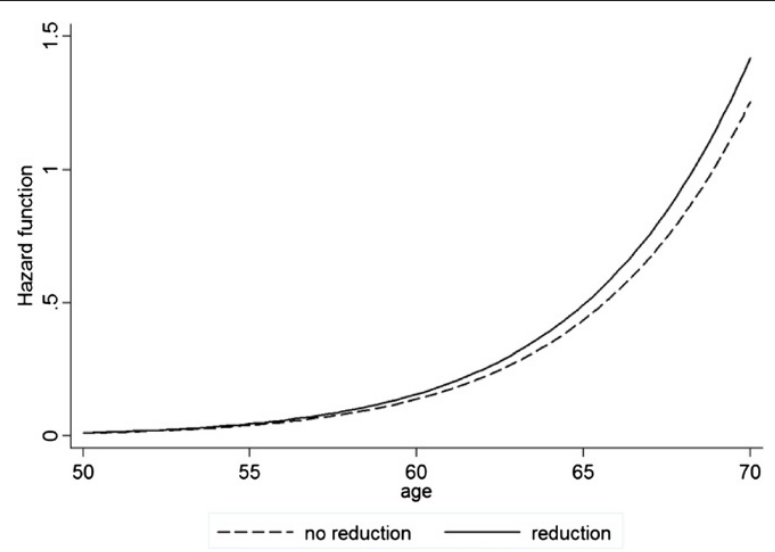

Figure 5 Retirement hazard, by reduction status (Reduction B). Source: Computations from the authors based on the "Transition to Retirement" module data, 2006. 


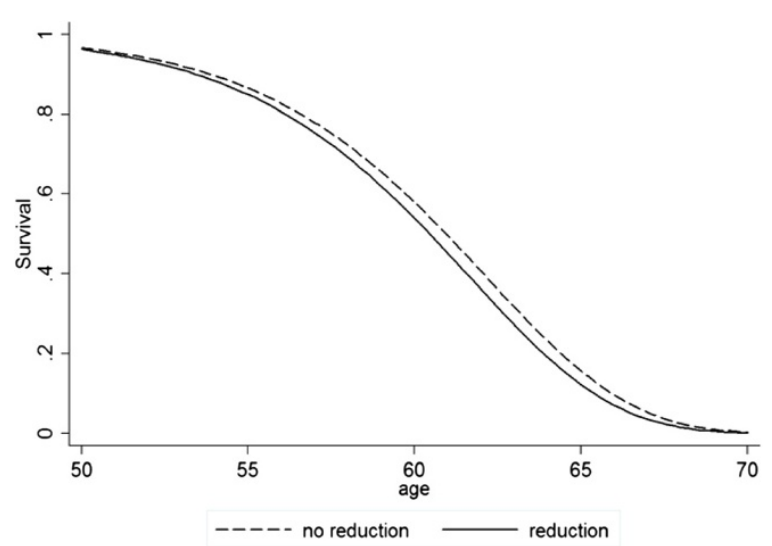

Figure 6 Survival curve, by reduction status (Reduction B). Source: Computations from the authors based on the "Transition to Retirement" module data, 2006.

Until August 2005, Portuguese workers were eligible to early retirement benefits as long as they comprise the following conditions: at least 55 years old and a working career of 30 complete calendar years. Although eligible, more than half of the workers who remain in the labour force state the need of obtaining a sufficient household income as the main reason to keep working. Conditional on being in the labour force, more than $2 / 3$ of the workers who did not reduce hours of work report the above reason to remain in the labour force while it is the reason pointed by $50 \%$ of those who have reduced hours of work. Additionally, more than $30 \%$ of the employed individuals that have reduced hours of work say they continue to work to increase retirement benefits against $20 \%$ of the answers for those that have not reduced working hours. The percentage that keeps working for nonfinancial reasons is higher $(14 \%)$ for subjects with hours' reduction than for those that have not reduced hours of work (9\%). There seems to be different financial motivations between individuals that reduce hours of work and those who do not.

When someone chooses to reduce hours of work he/she knows that their labour earnings will suffer a reduction. In a country with low average wages, like Portugal, with no partial retirement mechanisms that decision embodies relevant financial implications. Therefore, either the individual has a financial safety net that allows him/her to supplement the drop in labour income with savings from previous periods or has other types of income (such as rents, interests, etc.) allowing him/her to accommodate a wage reduction. If this is the case, the same individual will be willing to retire at early ages despite the pension reduction.

Those who do not reduce hours of work may face stronger financial constraints. They may have to work full-time for as long as possible and, therefore, exit from the labour force later.

Reducing hours of work before permanently leaving the labour force is believed to be a potentially useful measure to improve the attractiveness of work for older workers. This research, however, finds an association between working hours' reduction and retirement at earlier ages. Workers that choose to reduce their working schedule appear to be preparing their exit from the labour force rather than delaying it.

A reduction of hours of work is not very usual in the Portuguese labour market and this is, perhaps, the result of deficient opportunities provided by employers when it comes to flexibility in hours of work. If that is true, those older workers that actually reduce hours of work may be employed in firms that can offer phased retirement opportunities. 
On the other hand, reducing hours of work implies a decline in labour earnings. In Portugal there are no partial retirement mechanisms, that is, the possibility of accumulating part-time wage with part-time retirement. Partial retirement could smooth the transition from active life into retirement, motivating workers to work longer while reducing hours of work with no significant income loss.

With these data we cannot tell if those who have reduced hours of work have more income sources. In effect, the lack of variables associated with financial incentives is a major drawback in the analysis. Also, the static, cross-sectional nature of the data does not allow us to explore some dynamic features of relevance in the study of the retirement behaviour. These include the evolution of working hours in the latest years in the labour force as well as the correspondent change in wages, supplemented by information on Social Security incentives.

The use of panel data with information on income and wealth variables, on Social Security benefits, on hours of work and also on the moment that the reduction took place would allow us to get more solid conclusions on the relevance of hours' flexibility among active ageing policies. Disentangle what is behind this positive association between reduction and the retirement hazard for the Portuguese labour market remains a topic for future research.

\section{Endnotes}

${ }^{1}$ Age discrimination laws prohibit discrimination in hiring, promotion, wages or firing on the grounds of age. These laws may also forbid the inclusion of statements or specifications in job notices, or advertisements, of age preference and limitations; the laws can additionally prohibit mandatory retirement based on age.

${ }^{2}$ Stylized facts show that labour force participation rates are smaller for older workers (aged 55-64) than for prime-age workers (25-54 years old).

${ }^{3}$ In 2007, part-time employment in Portugal accounted for $10 \%$ of overall employment (European Commission 2007).

${ }^{4}$ The web appendix is available here http://www.eeg.uminho.pt/economia/mangelo/ appendix/appendix_hours.pdf.

${ }^{5}$ Additionally, besides the above mentioned exclusions, there are 19 observations missing for the Reduction variable and, for retirees, there are 7 observations missing for the variable used as proxy for the retirement age.

${ }^{6}$ Of the individuals reporting hours' reduction $1 / 3$ work in full-time jobs. Overall, only $8 \%$ of the individuals in the sample are in part-time employment.

${ }^{7}$ In 1929, mandatory schooling in Portugal comprised 3 years and, in 1955, it increased by 1 year for men. Only in 1961 mandatory schooling was standardized in 4 years for both men and women and, three years later, it was increased by 2 years; a law passed in 1986 set it at 9 years for students with first school registration in the 1987/1988 academic year and subsequent years. Hence, in 1995/1996 mandatory schooling comprised 9 years.

${ }^{8}$ The Nelson-Aalen estimator is a non-parametric estimator of the cumulative hazard function consisting of a staircase function. The steps are located at each observed death time and the vertical size of the steps is computed as $1 /$ (number at risk), where (number at risk) is the count of subjects just before the death that are still observed to be alive. 
${ }^{9}$ After age 65 the probability of survival is around 0.17 , indicating that at that age roughly $83 \%$ of the sampled individuals were out of the labour force (in the web appendix to this paper) (Additional file 1: Appendix D).

${ }^{10}$ The Nelson-Aalen cumulative hazard functions, by reduction status (in the web appendix) (Additional file 1: Appendix D) reveal that the hazard increases at a higher rate for those who reduce hours of work than it does for the individuals who do not reduce hours of work.

${ }^{11}$ The survivor function is given by exp $\left(-\gamma t^{\alpha}\right)$.

${ }^{12}$ Cited from Ajzen (2005).

${ }^{13}$ If this module is to be surveyed in the future we suggest the inclusion of a question to obtain the age of retirement.

${ }^{14}$ In Question 3b there are 2,535 observations missing for the intended age of retirement of currently employed individuals. Therefore, from the sample of 3,319 employed individuals (see Table 2), taking out 2,535 who did not report the intended age of retirement, we end up with 784 observations for those employed. Adding to this figure the initial 1,954 observations for retirees, we get 2,738 observations available in the equations using the variable Reduction $B$.

${ }^{15}$ Older people have a higher hazard of exit from the labour force.

${ }^{16}$ In our analysis we find a positive association between the reduction in working hours and retirement at earlier ages but, within our analysis, one cannot claim causality. Due to data limitations we cannot, in a satisfactory way, estimate a causal effect.

${ }^{17}$ Chi-squared statistic for 15 degrees of freedom is equal to 90.91 ( $\mathrm{p}$-value $=0.00$ ).

${ }^{18}$ One can argue that the Portuguese case is very particular (with a very low share of parttime employment and the impossibility of a part-time retirement mechanism) and that the extrapolation of results is difficult. However, comparable aggregate statistics for European Union countries (available at http://epp.eurostat.ec.europa.eu/portal/page/portal/employment_ unemployment_lfs/data/database) - obtained through the 2006 Transition to Retirement module that was enforced in each EU country - seem to suggest that the availability of more flexible working time arrangements would have a small effect on retaining older individuals in the labor force. On average, almost $3 / 4$ of the employed persons in the EU27 state that they would not have stayed (or will not stay) longer at work if flexible working time arrangements were available.

${ }^{19} \mathrm{Chi}$-squared statistic for 15 degrees of freedom is equal to 53.96 ( $\mathrm{p}$-value $=0.00$ ).

${ }^{20}$ The difference results from comparing estimates for the "Industrial" category in Columns (1) and (2), Table 8, with columns (1) and (3) of Table 7.

${ }^{21}$ We have also run each regression excluding the public sector. Results are not different from the ones reported. Additionally, several robustness tests were performed using other parametric and semiparametric models. Results remained unchanged and these can be obtained from the authors upon request.

\section{Additional file}

Additional file 1: Appendices to the paper "Hours of work and retirement behaviour" by Sofia Machado and Miguel Portela. Appendix A: Overview of relevant legislation changes on retirement pension's access. Appendix B: Questionnaire of the module "Transition to Retirement". Appendix C: Definitions of industry and worker type.

Appendix D: Survival and hazard functions (Portugal Portuguese legislation 1990). 


\section{Competing interests}

The IZA Journal of European Labor Studies is committed to the IZA Guiding Principles of Research Integrity. The authors declare that they have observed these principles.

\section{Acknowledgements}

We wish to thank Ana Rute Cardoso, this paper has benefited from her helpful questions and detailed comments. We thank an anonymous referee for pointing us valuable comments. We also thank participants of the 2011 European Economic Association \& Econometric Society Meeting (Oslo) and of the $2^{\text {nd }}$ International Workshop on the SocioEconomics of Ageing (Lisbon) for their critics and suggestions. The financial support of FCT (Portuguese Foundation for Science and Technology) under the grant SFRH/BD/31103/2006 (as part of the PhD grant of the first author) is gratefully acknowledged. Both authors acknowledge financial support provided by the European Regional Development Fund (ERDF) through the Operational Program Factors of Competitiveness (COMPETE); and by national funds received through FCT. The authors also thank the Portuguese Statistics Office (INE) for granting access to the Labour Force Survey microdata, under the established protocol with the Ministry of Science and Higher Education. Any errors and opinions expressed are those of the authors.

Responsible editor: Alan Barrett

\section{Author details}

${ }^{1}$ Instituto Politécnico do Cávado e do Ave and NIPE, Campus do IPCA, Barcelos 4750-810, Portugal. ${ }^{2}$ NIPE/Universidade do Minho and IZA, Bonn, Campus de Gualtar, Braga 4710-057, Portugal.

\section{Received: 9 October 2013 Accepted: 14 April 2014}

Published: 18 Aug 2014

\section{References}

Adams SJ (2004) Age discrimination legislation and the employment of older workers. Labour Econ 11:219-241 Ajzen I (2005) Attitudes, personality and behavior. Open University Press, McGraw- Hill

Allison PD (1984) Event history analysis, Sage University Paper series on Quantitative Applications in the Social Sciences. Sage, Beverly Hills, CA, pp 07-046

Ashenfelter O, Card D (2002) Did the elimination of mandatory retirement affect faculty retirement?". Am Econ Rev 92(4):957-980

Bartel AP, Sicherman N (1993) Technological change and retirement decisions of older workers. J Labor Econ 11(1):162-183

Belloni M, Rob A (2008) "The importance of financial incentives on retirement choices: new evidence for Italy.". Tinbergen Inst Discussion Paper 52/3

Blau DM, Shvydko T (2007) "Labor market rigidities and the employment behavior of older workers.", IZA Discussion Paper., p 2996

Burtless G, Moffitt RA (1985) The joint choice of retirement age and postretirement hours of work. J Labor Econ 3(2):209-236

Burtless G, Quinn JF (2000) "Retirement trends and policies to encourage work among older Americans.". Boston Coll Work Paper Econ 436

Cameron CA, Trivedi PK (2005) Microeconometrics: methods and applications. Cambridge University Press, Cambridge

Commission E (2007) Employment in Europe 2007. Office for Official Publications of the European Communities, Luxembourg

Commission E (2008) Employment in Europe 2008. Office for Official Publications of the European Communities, Luxembourg

Dorn D, Sousa-Poza A (2005) The determinants of early retirement in Switzerland. Schweiz Zeitschrift Volkswirtschaft Stat 141(2):247-283

Dorn D, Sousa-Poza A (2010) "Voluntary' and 'involuntany' early retirement: an international analysis.". Appl Econ, forthcoming 42(4):427-438

Dugan JE (1984) The labor-force participation of older workers. Ind Labor Relat Rev 37(3):416-430

Fishbein M, Ajzen I (1975) Belief, attitude, intention, and behavior: an introduction to theory and research. AddisonWesley, Reading, MA

Friedberg $L$ (2003) The impact of technological change on older workers: evidence from data on computer use. Ind Labor Relat Rev 56(3):511-529

Gielen AC (2009) Working hours flexibility and older workers' labor supply. Oxf Econ Pap 61(2):240-274

Gustman AL, Steinmeier TL (1984) Partial retirement and the analysis of retirement behavior. Ind Labor Relat Rev 37(3):403-415

Gustman AL, Steinmeier TL (2004) "Minimum hours constraints, job requirements and retirement.". NBER Working Paper, Cambridge, p 10876

Hanoch G, Honig M (1983) Retirement, wages, and labor supply of the elderly. J Labor Econ 1(2):131-151

Hutchens R, Grace-Martin K (2006) Employer willingness to permit phased retirement: why are some more willing than others?". Ind Labor Relat Rev 59(4):525-546

Hutchens R, Papps KL (2005) Developments in phased retirement". In: Clark RL, Mitchell OS (eds) Reinventing the Retirement Paradigm. Oxford University Press, Oxford, pp 133-161

Johnson RW, Favreault MM, Jones LY (2000) "The interrelationships among spousal work status, spousal health and retirement in the HRS.". In: Paper prepared for the Second Annual Conference of the Retirement Research Consortium, May., Washington, D.C

Lazear EP (1979) Why is there mandatory retirement?". J Polit Econ 87(6):1261-1284 
Martins PS, Alvaro N, Pedro P (2009) "Increasing the legal retirement age: the impact on wages, worker flows and firm performance.", IZA Discussion Paper., p 4187

Mitchell OS, Fields GS (1984) The economics of retirement behaviour. J Labor Econ 2(1):84-105

Neumark D, Stock WA (1999) Age discrimination laws and labor market efficiency. J Polit Econ 107(5):1081-1125

Osberg L (1993) Is it retirement or unemployment? Induced 'retirement' and constrained labour supply among older workers. Appl Econ 25:505-519

Portugal, National Statistics Office (INE) (2005) Explanation document from the Labor Force Survey's 2006 module, "Transition to Retirement"

Portugal, National Statistics Office (INE) (2009) Data from the Labor Force Survey in magnetic medium

Portugal, National Statistics Office (INE) (2009) statistics obtained on November 2009 from www.ine.pt

Portugal Portuguese legislation (2009) (Diário da República) obtained from dre.pt

Quinn JF (1977) Microeconomic determinants of early retirement: a cross-sectional view of white married men. J Hum Resour 12(3):329-346

Ruhm CJ (1990) Bridge jobs and partial retirement. J Labor Econ 8(4):482-501

Shannon M, Grierson D (2004) Mandatory retirement and older worker employment. Can J Econ 37(3):528-551

10.1186/2193-9012-3-16

Cite this article as: Machado and Portela: Hours of work and retirement behaviour. IZA Journal of European Labor Studies 2014, 3:16

Submit your manuscript to a SpringerOpen ${ }^{\circ}$ journal and benefit from:

- Convenient online submission

- Rigorous peer review

- Immediate publication on acceptance

- Open access: articles freely available online

- High visibility within the field

Retaining the copyright to your article

Submit your next manuscript at $>$ springeropen.com 